\title{
EL DESPERTAR DEL TURISMO URBANO EN ESPAÑA: BAÑOS DE MAR, OCIO Y URBANISMO EN A CORUÑA, 1900-1935*
}

\author{
Elvira Lindoso-Tato \\ Margarita Vilar-Rodríguez \\ Universidad de A Coruña
}

\section{RESUMEN}

La ciudad de A Coruña presentó un notable crecimiento económico, demográfico y urbanístico en el primer tercio del siglo XX cuando se desarrollaron una serie de actividades que perseguían insertar a la población en las incipientes corrientes turísticas de la época. El trabajo ofrece nuevos datos sobre las empresas, las infraestructuras y los proyectos ligados al sector turístico coruñés para estudiar el alcance de dicha inserción. Los resultados revelan que el turismo era una industria con potencial y con repercusión efectiva en los resultados económicos regionales y locales.

Palabras clave: baños de mar, urbanización, turismo, España, Coruña, siglo XX.

The awakening of urban tourism in Spain: seaside resorts, leisure and urbanism in A Coruña, 1900-1935

\section{ABSTRACT}

The city of A Coruña showed a remarkable economic, demographic and urban growth in the first third of the 20th century, when a series of activities pursued insert

Fecha de recepción: 25 de marzo de 2017.

Fecha de aceptación: 17 de octubre de 2017.

Área de Historia e Instituciones Económicas. Departamento de Economía. Facultad de Economía y Empresa. Universidad de A Coruña. Campus de Elviña, s/n. 15071 A CORUÑA (España).E-mail: elviralt@udc.es, mvilar@ udc.es

* Este trabajo forma parte de una investigación más amplia realizada en el marco del proyecto Historia del Turismo en Galicia. Orígenes y Desarrollo en el siglo XX, Ref. HAR2014-52023-C2-2-P dirigido por Rafael Vallejo Pousada y financiado por el Ministerio de Economía y Competitividad. Asimismo, las autoras, Elvira Lindoso-Tato (ORCID: 0000-0003-1004-5360) y Margarita Vilar-Rodríguez (ORCID: 0000-000I-9082-2734), forman parte del Grupo de Estudios de Historia de la Empresa de la Universidad de A Coruña. 
the population in emerging tourism trends of the time. This research offers new data on companies, infrastructures and projects linked to the tourist sector in Coruña in order to study the scope of this insertion. The results reveal that tourism in Spain was an industry not only with potential but also with an effective impact on regional and local economic performance.

Keywords: seaside resorts, urbanization, tourism, Spain, Coruña, XXth century.

\section{INTRODUCCIÓN}

Al despertar el siglo XX España había iniciado su camino para transformarse en un país de turismo con empresas, organizaciones y un equipamiento capaz de convertir este sector en parte sustancial de su estructura económica. El patrimonio turístico nacional -expresado en oferta de establecimientos de hospedaje, balnearios y casas de baños marítimas- se multiplicó por 2,4 entre 1900 y $1933^{1}$. Con diferencias regionales, una incipiente industria turística se puso en marcha al servicio de una minoritaria población nacional y extranjera viajera -clases altas y clases medias acomodadas en expansión-.

A pesar de su relativo atraso económico, Galicia ocupaba posiciones relevantes en el ranking turístico español durante el periodo analizado. Por un lado, la historiografía ha revelado su liderazgo en el turismo balneario desde mediados del siglo XIX ${ }^{2}$. Por otro lado, y a pesar de su débil crecimiento urbano en comparación con otros territorios, las ciudades gallegas ofrecieron una amplia oferta de establecimientos hoteleros y de restauración. Dentro de este apartado destacaron dos ciudades portuarias, Vigo y A Coruña, junto con una ciudad vinculada al turismo religioso, Santiago de Compostela. Recordemos que, precisamente, las raíces mismas del turismo se encuentran en el ámbito urbano $^{3}$. Valga como ejemplo el caso de las ciudades-balneario del Norte de España de finales del siglo XIX y principios del $\mathrm{XX}^{4}$. Pero, ¿qué convierte a una ciudad en destino turístico? Varios factores pueden ejercer una notable influencia sobre el desarrollo turístico urbano: la existencia de un patrimonio cultural y monumental, los activos naturales del paisaje urbano, la celebración de ferias o congresos relacionadas con el mundo de los negocios o el académico o el desarrollo de actos lúdicos-deportivos.

Nuestro objeto de estudio, la ciudad de A Coruña, situada en una península natural, contaba a principios del siglo XX con dos atractivos importantes vinculados al mar: un activo puerto punto de salida de emigrantes hacia el continente americano y más de dos kilómetros de playas urbanas que constituían un emplazamiento óptimo para las casas de baños y otras actividades lúdicas. Desde el puerto coruñés se embarcaron en la primera década del siglo XX más de un cuarto de millón de pasajeros; lo que generó efectos de

\footnotetext{
1 Vallejo, Lindoso y Vilar (2016).

2 Alonso, Lindoso y Vilar (2011).

3 Acerca de las fases experimentadas por el concepto de turismo urbano, véase Cases y Marchena (2005).

4 Violier y Zárate (2007).
} 
arrastre sobre un gran número de actividades de hostelería y restauración. La corriente migratoria fue perdiendo impulso en las décadas siguientes de manera simultánea a la expansión de otros servicios bancarios y comerciales. Por otra parte, la vitalidad demográfica y económica de la ciudad potenció la expansión urbanística y un gran número de actividades de ocio.

¿Cuáles eran los activos de la ciudad que podían ejercer de elementos de atracción turística? Una población y unos servicios urbanos en crecimiento, un puerto dinámico, una riqueza monumental que empezaba a ser reconocida y, en especial, un litoral urbano constituían los principales elementos diferenciadores de la población. De hecho, la ciudad de A Coruña pasó de unos 43 mil habitantes en 1900 a cerca de 62 mil en 1930, lo que supuso aumentar su población en casi un 50\% y consolidó su liderazgo en el ámbito gallego ${ }^{5}$. Durante estos años, el ayuntamiento coruñés anexionó barrios periféricos, se trazaron y pavimentaron nuevas avenidas hacia la zona del segundo ensanche, donde crecían las construcciones de edificios cada vez más altos, y se dotó a la ciudad de suministros básicos y mejoras en la red de transporte urbano. Desde principios del siglo $\mathrm{XX}$, A Coruña contó con una red de tranvías urbana (Compañía de Tranvías de La Coruña, 1902), primero de tracción animal y más tarde eléctrica ${ }^{6}$. Un año después se constituyó la Sociedad Anónima de Aguas de La Coruña (1903) que inauguró el suministro en 1908. Por otro lado, la ciudad ya contaba con iluminación por gas fluido desde mediados del siglo XIX; a la que se sumaría en años venideros el alumbrado eléctrico público. Además, a principios del siglo XX se inició uno de los proyectos más ambiciosos en la historia del puerto de A Coruña con la construcción de la Dársena de La Marina, los jardines de Méndez Núñez y del Varadero del Parrote ${ }^{7}$. Esta obra supuso una profunda remodelación y embellecimiento de la fachada portuaria de la ciudad, que ganó terreno al mar con el relleno de una considerable superficie, y se protegió de los duros temporales del Atlántico con un dique de abrigo. El proyecto del Muelle de Trasatlánticos, finalizado en 1936, redondeó una obra monumental que reformó por completo esta cara de la ciudad. Por último, la construcción de la Ciudad Jardín puso en valor el atractivo de la ciudad para disfrutar de nuevos estilos de vida.

Partiendo de este contexto, este trabajo tiene como principal objetivo el estudio del stock turístico coruñés durante el primer tercio del siglo $\mathrm{XX}$, vertebrado en torno a tres claves: las casas de baños, los establecimientos hoteleros y las empresas de ocio, y los primeros proyectos urbanísticos asociados a un nuevo estilo de vida urbano. Para ello analizaremos en los siguientes apartados los principales proyectos empresariales que tomaron cuerpo en A Coruña en torno al turismo y otras actividades de ocio durante la citada época. En conjunto, comprobaremos que se trataba de un turismo menos lujoso que el de otras capitales del norte, pero que contribuyó a consolidar a la ciudad como centro de servicios y puso las bases de un incipiente turismo urbano.

5 Vázquez y De Juana (2005: 413).

6 Martínez y Piñeiro (2001).

7 Consúltese web del puerto de A Coruña, http://www.puertocoruna.com. 


\section{TURISMO Y SALUD EN TORNO AL MAR: LAS CASAS DE BAÑOS DE A CORUÑA}

A Coruña trató de incorporarse a la ola turística que empezaba a bañar a España desde finales del siglo XIX. Una de las primeras guías de la ciudad, publicada en 1911 y titulada Guía práctica para el viajero de la Sociedad de Hoteleros, Fondistas y similares legalmente constituida en La Coruña ponía en valor el amplio abanico de monumentos y actividades de ocio que la ciudad ofrecía a los forasteros. Pero destacaba bajo el epígrafe "Playas y balnearios", el especial atractivo de la "hermosa playa de Riazor, uno de los más admirables sitios de la población y uno de los paseos más concurridos durante los días de verano"8. Años más tarde, el futuro turístico de la ciudad quedaría ligado en gran medida a sus arenales ${ }^{9}$.

La amplia costa herculina, con sus dos bahías, sirvió de escenario para el establecimiento y explotación de una serie de casas de baños desde la década de 1830 (cuadro 1). Los balnearios marítimos iniciaron su expansión en varias ciudades litorales españolas desde ese decenio a imitación de las estaciones balnearias marítimas fundadas en Inglaterra desde mediados del siglo XVIII; un modelo difundido posteriormente por la Europa continental. Walton (1997) sostiene que la moda del baño de mar con fines terapéuticos y profilácticos bajo dirección o consejo médico constituye una invención inglesa. Primero la aristocracia y la pequeña nobleza, luego los comerciantes, industriales y profesionales y por último la clase media-baja y la trabajadora se sumaron a esta moda del seaside resort durante el siglo XIX.

A Coruña reunía las condiciones naturales necesarias para incorporarse a la nueva corriente turística-medicinal. El baño en las playas y ensenadas de la ciudad resultaba habitual desde el siglo XIX. Desde mediados de esta centuria el ayuntamiento recibía unos ingresos por el empleo de las casetas para bañistas instaladas en las principales playas urbanas de aquel entonces (Parrote ${ }^{10}$, Riazor y Orzán). A finales de siglo la explotación de casas de baños exigió requisitos municipales específicos de construcción y explotación. Las primeras empresas locales de baños comenzaron funcionando bajo una concesión administrativa del dominio público y estaban sometidas a estrictas normativas que restringían el uso y el acceso a las playas tanto a empresarios como a clientes ${ }^{11}$.

Las primeras referencias disponibles sobre balnearios marítimos en A Coruña datan de 1835, cuando el ayuntamiento proyectó construir un balneario público mediante la suscripción de acciones. Esperaban emplazarlo en el Foso de la Puerta Real y construir 34 departamentos con sus correspondientes pilas de mármol y zinc para tomar baños de agua caliente y fría con un presupuesto de 36.606 reales. Pero el erario público no estaba en condiciones de asumir todo el coste y esperó sin éxito la colaboración del capital privado ${ }^{12}$. Finalmente, un empresario local instaló en 1837 la primera casa de baños, en el Parrote, una zona de baño situada al pie de la ciudad vieja y mejor resguardada del viento y las

8 Guía práctica para el viajero (1911: 46).

9 AMC. Año 1927. Expediente de arriendo y de obras de mejora y mantenimiento del balneario municipal de Riazor, leg. 132.

10 La playa del Parrote no existe hoy en día. Víctima de la expansión urbana, en su lugar se ubica el complejo deportivo de La Solana, véase Monterroso (1992).

11 Gil (2007).

12 Para esta parte, Tettamancy (1900: 426-429) y Meijide (1997: 323-343). 
resacas que otras playas coruñesas. Contaba con dos departamentos, uno para hombres y otro para mujeres y niños, que se alquilaban a precios económicos. Nuevos balnearios se sumaron a éste en los años siguientes pero corrieron una suerte desigual (cuadro 1).

\section{Cuadro 1}

CASAS DE BAÑOS EN A CORUÑA, 1835-1935

\begin{tabular}{|c|c|c|c|}
\hline Establecimiento & Fundador & Inicio/Duración & Notas \\
\hline Proyecto de Balneario & Municipal & 1835 & Fallido \\
\hline Balneario particular & José Fernández & 1837-siglo XX & $\begin{array}{l}\text { O Parrote/frente } \\
\text { rampa calle Montoto }\end{array}$ \\
\hline $\begin{array}{l}\text { Balneario de madera } \\
\text { desconocido }\end{array}$ & n.d. & c. 1837 & $\begin{array}{l}\text { Situado tras Teatro } \\
\text { Principal }\end{array}$ \\
\hline Casa de baños flotante & Municipal & 1850 & Riazor \\
\hline Balneario flotante & Francisco Pola & c. $1854-56$ & $\begin{array}{l}\text { O Parrote/frente } \\
\text { rampa calle Montoto }\end{array}$ \\
\hline Casa de baños & $\begin{array}{l}\text { Eduardo y Esteban } \\
\text { Cervigón }\end{array}$ & 1864 & O Parrote/Estacada \\
\hline Balneario público & Municipal & 1874 & Riazor \\
\hline La Primitiva & Guillermo Howland & 1874-1949 & Riazor \\
\hline Casa de baños & Familia Cervigón & c. 1875 & $\begin{array}{l}\text { C/Socorro } \mathrm{n}^{\circ} 20, \\
\text { inmediata a playa del } \\
\text { Orzán }\end{array}$ \\
\hline Baños de mar & Melchor Linares García & Solicitado en 1878 & Pelamios \\
\hline $\begin{array}{l}\text { Casa de baños no- } \\
\text { litoral }\end{array}$ & n.d. & c. 1878 & Santa Margarita \\
\hline Casa de baños & Eduardo Cavia & 1884 & Punta del Parrote \\
\hline La Salud & Juan Villardefrancos & $1886-1963$ & Riazor \\
\hline Casa de baños & $\begin{array}{l}\text { M. Fernández Salgado } \\
\text { (asociado con R. Fernández } \\
\text { Vaamonde) }\end{array}$ & 1886 & Parrote \\
\hline La Perfecta & $\begin{array}{l}\text { Bernardino de Aspiazu } \\
\text { Álvarez }\end{array}$ & c.1888-Fin.1897 & Riazor \\
\hline Casa de baños & Baña y Fernández & 1889 & Parrote \\
\hline Casetas & Tomás Rico Gimeno & 1899 y 1910 & Riazor \\
\hline Balneario & $\begin{array}{l}\text { Ruperto Fernández } \\
\text { Vaamonde }\end{array}$ & $\begin{array}{l}\text { En funcionamiento } \\
\text { a principios del } \\
\text { siglo XX }\end{array}$ & Parrote \\
\hline Casa de baños & Rafael Miguel Ugía & c. $1913-1920$ & Real 90 \\
\hline Casa de baños & $\begin{array}{l}\text { José María González } \\
\text { Fernández }\end{array}$ & c. 1913 & Real 9 \\
\hline Casa de baños & Victoriano Sande & c. $1930-1935$ & Cantón Grande 3 \\
\hline
\end{tabular}

Fuente: Tettamancy (1900: 426-429); Meijide (1997: 323-343), Lindoso (2006); BOPC nº 101-131 (1910-1913); AMC. Caja 5121. Años 1920-21; Matrícula de la Contribución Industrial; COCINC. Matrícula de Industrial. Capital 1927 a 1932. Cámara de Comercio; Censos de la capital. 1935 al 40. Cámara de Comercio; AMC. C.7051. Año 1924. Expedientes de arriendo y obras de mejora y mantenimiento del balneario municipal de Riazor, leg. 125. 
Por fin, en 1850, se construyó un balneario público, promovido por el ayuntamiento y financiado con 4.000 reales procedentes de la beneficencia. En este caso se situó en la otra parte de la península, la playa de Riazor, por entonces los arrabales de la ciudad. Estas instalaciones desaparecieron sin rastro seguramente por el azote de un temporal. Más éxito obtuvo el siguiente balneario municipal que se edificó a orillas del mismo arenal con fines benéficos en el año 1874. El establecimiento contaba con instalaciones de calidad superior a la media: un salón de descanso y una fonda, entre otras cosas. Durante la temporada estival un ómnibus realizaba viajes periódicos desde distintos puntos de la ciudad a la casa de baños. Pero el ayuntamiento no estaba satisfecho.

En 1882 proyectaron construir una nueva estación balnearia en Riazor. Con este fin, el arquitecto municipal Faustino Domínguez Coumes-Gay se desplazaría a Santander, San Sebastián y Biarritz - tres de los grandes centros turísticos costeros de la épocapara estudiar sus casas de baños, casetas y accesorios. En definitiva, pretendía visitar los resorts marítimos más renombrados de la costa española y uno de los más famosos de la francesa -Biarritz- cerca de la frontera, que habían importado con éxito la moda de los baños de mar y sus actividades anexas ${ }^{13}$. En España, el liderazgo en materia de turismo marítimo le correspondió inicialmente al litoral cantábrico, zona hacia la que se dirigían muchos habitantes del centro del país para escapar de los sofocantes estíos. En particular, San Sebastián contaba con una larga trayectoria histórica como estación balnearia marítima y centro de veraneo de la familia Real desde la primera mitad del siglo XIX. Algo más tarde, Santander se sumó a esta nueva moda e intentó poner en valor las playas del Sardinero ${ }^{14}$. El desarrollo del transporte ferroviario y las líneas de vapores contribuyeron a facilitar la comunicación con la Meseta y entre las diversas localidades costeras. Entre la década de 1890 y la I Guerra Mundial, la red de estaciones balnearias marítimas se extendió hacia Asturias (Gijón) y Galicia (A Coruña) ${ }^{15}$. En conjunto, la costa norte peninsular mantuvo un creciente atractivo turístico en torno a los baños de mar hasta la Guerra civil, favorecido por el comportamiento de las elites y por las recomendaciones médicas.

Sin embargo, el viaje del arquitecto se canceló y el proyecto de construcción de un nuevo balneario municipal en A Coruña no cuajó por motivos económicos. La renovación se pospuso y las instalaciones del balneario municipal de A Coruña creado en 1874 siguieron en activo -con algunas modificaciones- hasta el siglo XX. Durante esta centuria, el ayuntamiento entregó el servicio de explotación del centro de baños a la iniciativa privada ${ }^{16}$. Así, durante casi dos décadas, el establecimiento público estuvo administrado por capitalistas privados exceptuando el bienio 1922-1923 y 1926 (cuadro 2).

13 Los centros turísticos marítimos se habían extendido desde Inglaterra hacia el continente europeo. España se incorporó pronto a este proceso, véase Walton (1997).

14 Walton (1997), Gil (1992) y Larrinaga (2009).

15 Según Walton (1997), excepto en algunas playas de grandes ciudades, la extensión de las casas de baños resultó menor en la costa mediterránea.

16 AMC. C-7050. Año 1917. Expediente de arriendo y obras de mejora y mantenimiento del balneario municipal de Riazor, leg. 120. 
La gestión pública del primer período se saldó con buenos resultados económicos gracias a la renovación del balneario en el año 1922, a la que contribuyeron tanto el ayuntamiento como las elites mercantiles e industriales urbanas ${ }^{17}$.

\section{Cuadro 2}

\section{CONCESIONARIOS DEL BALNEARIO MUNICIPAL, 1910-1929 (PTS)}

\begin{tabular}{|l|r|r|r|}
\hline Arrendatario & Período & $\begin{array}{r}\text { Renta } \\
\text { anual }\end{array}$ & Inventario* \\
\hline $\begin{array}{l}\text { Eduardo Guillemette Álvarez (representado por José Juega } \\
\text { López) }\end{array}$ & $1910-1913$ & 2.005 & 7.331 \\
\hline Domingo Martínez Gutiérrez & $1914-1916$ & 3.021 & 24.108 \\
\hline Ramón Dorrego Fernandez & 1917 & 3.025 & 23.006 \\
\hline Ramón Dorrego Fernandez & 1918 & 3.025 & 23.018 \\
\hline Ramón Dorrego Fernandez & 1919 & 3.400 & \\
\hline Ramón Dorrego Fernandez & $1920-1921$ & 4.500 & \\
\hline Administración municipal & $1922-1923$ & & \\
\hline Ramiro Bravo Hernández (playa y ambigú) & $1924-1925$ & 10.105 & \\
\hline Administración municipal & 1926 & & \\
\hline Ramón Dorrego Fernández & $1927 ?$ & 4.000 & \\
\hline Ramiro Bravo Hernández & 1928 & 5.800 & \\
\hline Luis Juega & 1929 & n.d. & \\
\hline
\end{tabular}

* Valor de los efectos entregados a los concesionarios del balneario municipal. Fuente: AMC. Expediente de arriendo del balneario municipal de Riazor; C-7048. Año 1910; C-7050. Año 1917, leg. 94, 108 y 120; C-7051. Año 1924, leg. 124 y 125; Año 1927, leg.132 y 133.

La buena marcha del balneario de la Beneficencia Municipal atrajo también a empresarios como Isidoro Lozano Flores, quien ofreció al ayuntamiento establecer un servicio de restaurante en la playa de Riazor durante los meses de verano, aprovechando el personal y los recursos del gran hotel que pretendía inaugurar en A Coruña en 1923. El ayuntamiento rechazó la propuesta puesto que solía arrendar el servicio del ambigú de Riazor a cambio de un canon. Sin embargo, esta iniciativa resulta curiosa dado que Lozano buscaba la colaboración oficial para, según sus palabras, "contribuir a convertir a la ciudad en un centro de expansión y turismo para que así el forastero disfrute por menos dinero que en las playas de moda" 18 . Unos precios más bajos parecían la estrategia más adecuada a la hora de competir con las playas de moda de aquel entonces ubicadas en Santander y San Sebastián. En general, desconocemos los resultados durante la época de la gestión privada

17 AMC. Expediente de arriendo del balneario municipal de Riazor; C-7048. Año 1910; C- 7049. Año 1913; C-7050. Año 1917.

18 AMC. C-7050. Año 1917. Expediente de arriendo y obras de mejora y mantenimiento del balneario municipal de Riazor, leg. 120. 
del establecimiento. Sí sabemos que cuando el negocio revirtió de nuevo al municipio -hacia 1926- la clientela era abundante, puesto que se denunciaba la escasez de casetas de baños, y la recaudación no dejó de crecer $^{19}$. Y esto a pesar de que el establecimiento municipal competía con casas de baños privadas en el arenal de Riazor, instaladas con mayor confort desde el último cuarto del siglo XIX. Dos establecimientos particulares sobresalían por su entidad y longevidad: La Primitiva y La Salud; ambas próximas al chalet del balneario municipal y al palco de la música desde donde una banda amenizaba los paseos de los viandantes.

La Primitiva nació en la década de 1870 de la mano de un empresario de posible origen británico, Guillermo Howland de Quesada ${ }^{20}$. Se publicitaba como una gran casa de baños de agua de mar, dulce y minero-medicinales, lo que la diferenciaba en gran medida de la competencia. De este modo, junto a los baños de agua de mar y dulce, ofrecía baños de algas, jabonosos, gelatinosos, de brea y minerales con aguas procedentes de varios balnearios gallegos (Arteixo, Cuntis, Carballo, Lugo, A Toxa con sus sales) y de otros de la península. Disponía además, de duchas de todas clases, masaje, mecanoterapia, electroterapia, salón gimnasio, esgrima y tiro y salones de lectura y música. Los cuartos de baños estaban situados en una galería de setenta metros de largo que rodeaba un amplio jardín con una fuente de mármol en el centro ${ }^{21}$. La empresa pasó por diferentes manos hasta que el médico indiano oriundo de Laxe, Ramón Juega Charlín, la compró en 1903 y renovó las instalaciones. La familia Juega dirigió el establecimiento durante casi cuatro décadas tras la muerte del patriarca en 1905, actividad que combinaron con el arriendo ocasional de la casa de baños municipal (cuadro 2). Por otro lado, La Salud fue fundada por el médico municipal Juan Villardefrancos. El establecimiento se abrió al público en 1886 y disponía de 20 gabinetes de baños abiertos todo el año. Ofrecía una amplia gama de servicios (inhalación, gimnasia, etc.) e incluso una red de seguridad para los bañistas (maromas, salvavidas, etc.) ${ }^{22}$. Una década después la empresa pasó a manos del doctor Ramón Dorrego y se anunció como un gran instituto hidroterápico. El establecimiento disfrutaba de la concesión municipal de una parte de la playa y el mismo Dorrego arrendó la explotación del balneario de la Beneficencia durante algunos años ${ }^{23}$.

Estas instalaciones convivieron con otras pequeñas casas de baños abiertas durante el primer tercio del siglo XX (cuadro 1) ${ }^{24}$. Sin embargo, en vísperas de la Guerra civil, La Salud, el balneario de la Beneficencia municipal y La Primitiva, en este orden, constituían los principales contribuyentes por baños en la ciudad de A Coruña ${ }^{25}$. El proceso de

19 AMC. 1927. Expediente de arriendo y de obras de mejora y mantenimiento del balneario municipal de Riazor, leg. 132.

20 A finales de la década de 1870 , este propietario coruñés era dueño de una fábrica de cerveza denominada "La Herculina", AHPC. Manuel Devesa y Gago, leg. 10.099 (1878), no 877, ff. 3918 y ss.

21 Guía práctica para...(1911: 53-54).

22 Meijide (1997: 323-343).

23 AMC. 1927. Expediente de arriendo y de obras de mejora y mantenimiento del balneario municipal de Riazor, leg.132 y 133 .

24 Sus cuotas industriales son las más bajas en el segmento de los baños entre 1913 y 1935, COCINC. Censos de la capital. 1935 al 40. Cámara de Comercio.

25 La Salud tributaba por 35 baños, 3 duchas, 30 casetas y 3 personas de servicio; La Primitiva por 26 baños y una ducha y el Ayuntamiento por 82 casetas y 3 personas a su servicio, véase COCINC. Censos de la capital. 1935 al 40. Cámara de Comercio. 
expansión urbanística pondría fin a estas empresas en la etapa franquista ${ }^{26}$. Había llegado el fin de las estaciones marítimas decimonónicas, sustituidas por un nuevo modelo de explotación de los arenales más abierto y masivo.

\section{LA OFERTA DE ALOJAMIENTO, RESTAURACIÓN Y OCIO EN LA CIUDAD DE A CORUÑA}

Los veranos coruñeses comenzaron a gozar de fama creciente desde finales del siglo XIX. Dos hechos ejercían una notable influencia: por un lado, las citadas playas y sus balnearios marítimos y por otro lado, las fiestas veraniegas -corridas de toros incluidas- que amenizaban la temporada de baños de sus habitantes y de los forasteros que visitaban la ciudad $^{27}$. El mérito de estas fiestas le corresponde al alcalde Juan Flórez que trasladó hacia 1850 la tradición de las fiestas de María Pita y la feria anual de Santa Lucía a la temporada estival. Intereses turísticos en particular y económicos en general movían al gerente municipal: reanimar la economía urbana atrayendo a los turistas tanto nacionales como extranjeros y lograr la prosperidad pública constituían sus ambiciosos objetivos ${ }^{28}$. Si bien carecemos de estadísticas de los forasteros que visitaron la ciudad durante el primer tercio del siglo $\mathrm{XX}$, los testimonios escritos apuntan que ese turismo estaba compuesto tanto por turistas nacionales como extranjeros; sobre todo cruceristas ingleses que de camino al Mediterráneo recalaban en la ciudad atraídos por la visita a la tumba de su héroe nacional, el general Sir John Moore, ubicada en los Jardines de San Carlos ${ }^{29}$. Por tanto, aquí nos encontraríamos con las dos vías que seguía el desarrollo del turismo europeo de la época ${ }^{30}$ : una, la de los turistas que se desplazaban a un único destino, normalmente costero, y otra, más dinámica, donde los forasteros realizaban recorridos turísticos. El caso coruñés no resultaba aislado en la península. Ciudades como Málaga comenzaron a promocionarse como un destino turístico desde finales del siglo XIX, articulando su campaña turística en torno a tres elementos, su carácter marítimo, la Feria de Agosto y la Semana Santa ${ }^{31}$.

Desde principios del Novecientos, se multiplicaron los artículos de prensa y las diversas guías, planos y almanaques de la ciudad coruñesa que alababan las virtudes del verano coruñés. En las décadas de 1920 y 1930, podemos encontrar diversas publicaciones que reforzaban la función de la urbe como estación de veraneo. Valgan como ejemplo las de Acción Coruñesa: La Coruña: ciudad veraniega, 1920 y La Coruña: ciudad veraniega, 1921, A Coruña, Acción Coruñesa, Talleres del Noroeste, 1921. Otro modo de promoción consistía en editar el programa de las fiestas que se celebraban en los meses más calurosos

26 Monterroso (1992) y Hemeroteca LOC, "Las casas del agua del siglo XIX”, 24 de febrero de 2011.

27 San Sebastián constituye un ejemplo de cómo las fiestas, el casino y otros entretenimientos contribuían a prolongar la estancia de los veraneantes, véase Larrinaga y Pastoriza (2009) y Larrinaga (2015).

28 Hemeroteca LVG, "Primeras fiestas de María Pita", 7 de septiembre de 2015.

29 Hemeroteca ABC, Revista Blanco y Negro 13 de agosto 1933. Turismo británico. La sombra del héroe. Entendemos que esos turistas ingleses no creaban presión sobre la oferta hotelera de la ciudad dado que se alojaban en los trasatlánticos que realizaban esos cruceros.

30 Cirer (2014).

31 El último elemento se potenciaría sobre todo durante la década de 1920. Asimismo, debemos recordar que las especiales características climáticas de la ciudad malagueña permitieron su conversión en estación de invierno, Pellejero (2016). 
del año (La Coruña. Grandes Fiestas organizadas por el Comité de Festejos patrocinado por el Excmo. Ayuntamiento. Agosto de 1924). La creación de una comisión especial de "Paseos, Fiestas y Balnearios" en el ayuntamiento coruñés durante la década de 1930 supone una evidencia de la creciente importancia del turismo en la ciudad ${ }^{32}$. En la revista Blanco y Negro también se publicaron varios artículos sobre A Coruña como residencia estival haciendo hincapié en sus jardines y playas ${ }^{33}$.

Durante el primer tercio del siglo pasado, los atractivos turísticos de la ciudad sufrieron una considerable mejora gracias al crecimiento urbano y las posibilidades de ocio (cuadro 3). Junto al poderoso reclamo de sus casas de baños y sus animados paseos y jardines, la ciudad contaba con plaza de toros, teatros y salas de cine. Cabe destacar los salones Doré y París destinados a las sesiones cinematográficas; los teatros Rosalía y Linares Rivas ${ }^{34}$. Estos edificios habían sustituido al viejo Teatro Circo Coruñés, con el que acabó la piqueta en 1901, o el Teatro Circo Emilia Pardo Bazán, convertido en escombros en 1915. Por otro lado, el Circo de Artesanos fundado en el siglo XIX celebraba prestigiosos ciclos de conferencias y charlas de los temas más diversos, desde el antiguo Egipto, pasando por la botánica o la arquitectura. Simultáneamente, los mencionados festejos estivales iban alcanzando mayor popularidad y las sociedades deportivas y otros clubes ofrecían alternativas de ocio al aire libre.

Otra de las grandes contribuciones municipales al turismo urbano consistió en el establecimiento de una oficina de información turística -primera de su clase que se instaló en Galicia- que, entre otras funciones, promocionaba las celebraciones festivas, excursiones de todo tipo y otras actividades veraniegas (La Coruña. Estación de Verano. 1928. Centro Municipal de Información y Propaganda en el Palacio Municipal) ${ }^{35}$. Entre otras funciones, la Oficina de Turismo organizaba excursiones por Galicia, orientaba al forastero sobre rutas y alojamientos y publicitaba el cartel de fiestas y actos lúdicos celebrados en la ciudad $^{36}$. En agosto de 1933, la revista Blanco y Negro consideraba esta iniciativa como un paso firme hacia la "municipalización del turismo" en A Coruña. En sintonía con lo que está sucediendo en otros puntos de la península desde finales de la década de 1920, el consistorio coruñés pretendía convertirse en el eje central de la futura red turística gallega. Como parte de este proceso, y a imitación de otras capitales del norte, las autoridades optaron por impulsar el turismo urbano bajo el slogan "La ciudad de la sonrisa" 37 . Asimismo, al comenzar la década de 1930, editaron el Boletín Municipal y de Turismo (1930-1932) como un escaparate para la promoción de establecimientos y empresas turísticas locales.

32 AMC. Boletín Municipal y de Turismo no 11, A Coruña, julio 1931.

33 Hemeroteca ABC, Revista Blanco y Negro, 7 de septiembre de 1919, 2 de julio 1933, 9 julio 1933, 15 julio 1934.

34 Hemeroteca EIG, "Cuando en La Coruña abundaban los teatros", 18 de octubre de 2015.

35 En ciudades como Málaga y Barcelona, su integración turística contó con agentes promotores de primer orden como la Sociedad Propagandística del Clima y Embellecimiento de Málaga -posteriormente integrada en el Sindicato de Iniciativa y Propaganda de la misma ciudad-, y la Sociedad de Atracción de Forasteros de Barcelona, entidad de carácter mixto, véanse Pelllejero (2016) y Palou (2017).

36 Hemeroteca ABC, revista Blanco y Negro 13 de agosto 1933. Ejemplos Coruñeses. La municipalización del turismo.

37 Hoy en día superado por "La ciudad donde nadie es forastero". 


\section{Cuadro 3 \\ EMPRESAS DE ESPECTÁCULOS EN A CORUÑA, AÑ̃ 1927 (PESETAS CORRIENTES)}

\begin{tabular}{|l|r|}
\hline Empresa & Cuota* \\
\hline Empresa Plaza de Toros & $57.460,22$ \\
\hline Empresa Teatro Rosalía de Castro & $21.842,49$ \\
\hline Empresa Teatro Linares Rivas & $17.875,44$ \\
\hline Empresa Teatro Salón París & $2.757,92$ \\
\hline Empresa Salón Doré & 249,41 \\
\hline Empresa Teatro Salón Novedades & 34,25 \\
\hline Sociedad Real Club Deportivo & $17.793,46$ \\
\hline Sociedad Endem & 345,65 \\
\hline Empresa Kiosko la Terraza & $2.231,12$ \\
\hline Empresa Kiosko Alfonso & $1.152,57$ \\
\hline Sociedad Atlética & 569,60 \\
\hline Circo de Artesanos & 311,55 \\
\hline Sociedad Olímpico F. C. & 472,35 \\
\hline D. Jose Luis Valdés & 230,40 \\
\hline Rosales & 69,00 \\
\hline D. Ciriaco Blanco & 12,80 \\
\hline D. Juan Monelos Reveira & 49,25 \\
\hline D. Domingo Teijido & 155,52 \\
\hline Asociación prensa & 671,41 \\
\hline Dña. Carmen Abella & 152,42 \\
\hline
\end{tabular}

*cuotas de la contribución industrial y de comercio correspondientes a las funciones celebradas durante el citado año. Fuente: AMC. c. 5121.

Resulta indudable el interés municipal por integrar a la ciudad en el turismo nacional e internacional desde fechas tempranas. El citado alcalde Flórez fue consciente de esto desde mediados del siglo XIX. Pero, ¿y los intereses privados? La Guía práctica para el viajero de la Sociedad de Hoteleros, Fondistas y similares legalmente constituida en La Coruña (1911) recogía en su preámbulo que la Sociedad de Hoteleros, Fondistas y similares esperaba contribuir con nuevos proyectos empresariales al fomento de "las modernas corrientes de turismo" en la ciudad. El sector parecía ofrecer cada vez más atractivos a los inversores locales ${ }^{38}$. Uno de los proyectos más importantes de la época se realizó en 1919 con la construcción de un Gran Casino-Hotel en La Marina, junto a los jardines de Méndez Núñez, que rodeaban el puerto de la ciudad ${ }^{39}$. El grupo estaba

38 Guía práctica para...(1911: 8).

39 Hemeroteca EIG, "El Gran Casino-Hotel que nunca vio la luz", 19 de julio de 2015. 
encabezado por José Núñez Piroto y Enrique Núñez Lizarrague, miembros de la familia Núñez de Betanzos, que poseían un amplio holding empresarial ${ }^{40}$ y Rafael González del Villar, amigo de los anteriores y diseñador de algunas de sus fábricas y comercios. Se trataba de un arquitecto de referencia en la época, precursor del Colegio Oficial de Arquitectos de Galicia, que había diseñado edificios emblemáticos en la provincia ${ }^{41}$. Un año antes, los tres habían fundado el coruñés café-restaurante Núñez y González con un respetable capital de 60 mil pesetas ${ }^{42}$. En la nueva aventura empresarial les acompañó Francisco Oria González. Obtuvieron la cesión municipal por tiempo limitado de un solar en la zona de la Marina (donde se había ubicado el Teatro Circo Emilia Pardo Bazán), pero el proyecto finalmente no se llevó a cabo por falta de apoyo económico y por la dudosa viabilidad del negocio en una ciudad con deficientes comunicaciones y falta de sociedades recreativas para impulsar el turismo. Un pequeño reportaje sobre A Coruña publicado en Blanco y Negro en 1919 todavía mencionaba las dificultades de acceso a la población y la poca publicidad que se hacía de los encantos de la ciudad ${ }^{43}$.

A pesar de las expectativas incumplidas en torno a este plan turístico, A Coruña experimentó una profunda transformación en su estructura hotelera y de ocio hasta los años treinta; sin embargo, a mediados de la década, esta tendencia se frena como revelan los datos recogidos en el hospedaje de la Contribución Industrial (cuadro 4): entre 1904 y 1930, el número de contribuyentes se multiplicó por 2,3, mientras que entre 1930 y 1935 se produjo un pequeño retroceso. La Guía Oficial de Hoteles, Pensiones, Casas de Viajeros, Restaurante, Bares y Garages publicada por el Patronato Nacional de Turismo en el año 1929 y el Anuario Regional del Norte de España publicado en 1932 nos permiten estimar que la ciudad ofrecía más de 70 alojamientos para visitantes, entre hospedajes, fondas y hoteles, con aproximadamente 1.100 habitaciones y 1.655 plazas (cuadro 5). En consecuencia, podemos afirmar que la oferta de hospedaje había aumentado respecto a los recogidos en la guía de 1911 (59), a la vez que había crecido el número de hoteles de mayor capacidad y confort para los viajeros. Estos establecimientos convivieron con una constelación de fondas y pensiones orientadas a un público más modesto. De hecho, de los 40 hoteles registrados, solo 7 superaban las 50 habitaciones; el resto englobaba a pequeños establecimientos que a veces se anunciaban como hoteles aunque probablemente no pasarían de ser modestas casas de hospedaje. En conjunto, A Coruña se presentaba en el primer tercio del siglo XX como una de las capitales de provincia con mayor oferta hotelera después de Madrid, Barcelona, Sevilla, San Sebastián, Granada y Málaga ${ }^{44}$. La posición coruñesa resulta coherente con el lugar ocupado por Galicia en el conjunto nacional para el mismo periodo ${ }^{45}$.

\footnotetext{
40 Alonso, Lindoso y Vilar (2008).

41 "La arquitectura de Rafael González Villar en Betanzos", Anuario Brigantino 1985 y Garrido (1998).

42 RMC, Libro 21 de Sociedades, Hoja n ${ }^{\circ}$ 602, Inscripción 1 ${ }^{\mathrm{a}}$, ff. 162-163.

43 Hemeroteca ABC, Revista Blanco y Negro, 7 septiembre 1919, p. 53.

44 Dirección General de Empresas y Actividades Turísticas (1972).

45 Vallejo, Lindoso y Vilar (2016).
} 


\section{Cuadro 4 \\ BAÑOS, TRANSPORTE, JUEGOS, HOSPEDAJE Y RESTAURACIÓN EN LA MATRÍCULA INDUSTRIAL DE LA CIUDAD DE A CORUÑA, 1904-1920 (NÚMERO DE CONTRIBUYENTES Y CUOTAS)}

\begin{tabular}{|c|c|c|c|c|c|c|c|c|c|c|}
\hline \multirow{2}{*}{ Categoría } & 1904 & 1913 & $1920-21$ & 1930 & 1935 & 1904 & 1913 & 1920-21 & 1930 & 1935 \\
\hline & $\mathbf{n}^{0}$ & $\mathbf{n}^{0}$ & $\mathbf{n}^{0}$ & $\mathbf{n}^{0}$ & $\mathbf{n}^{0}$ & pts & pts & pts & pts & pts \\
\hline Casas de baños & 5 & 7 & 7 & 7 & 7 & 2.447 & 2.856 & 3.757 & 5.652 & 5.024 \\
\hline $\begin{array}{l}\text { Transporte (tranvía, agente } \\
\text { de ferrocarril, coches, } \\
\text { automóviles, carros, carretas, } \\
\text { barcas, vapores, alquiler } \\
\text { velocípedos, garaje depósito) }\end{array}$ & 74 & 93 & 92 & 87 & $14 *$ & 8.396 & 7.194 & 5.028 & 11.304 & $4.653^{*}$ \\
\hline $\begin{array}{l}\text { Restauración (bodegones, } \\
\text { mesones, tabernas, cafés, } \\
\text { restaurantes) }\end{array}$ & 93 & 112 & 202 & 310 & 389 & 8.058 & 19.721 & 30.115 & 85.086 & 88.398 \\
\hline $\begin{array}{l}\text { Hospedaje (hoteles, casas de } \\
\text { huéspedes) }\end{array}$ & 45 & 89 & 72 & 102 & 97 & 5.601 & 12.370 & 16.736 & 32.448 & 29.716 \\
\hline Juegos de mesa, fútbol & 26 & 28 & 21 & n.d. & n.d. & 4.767 & 5.726 & 4.492 & n.d. & n.d. \\
\hline TOTAL & 243 & 329 & 394 & 506 & 507 & 29.269 & 47.866 & 60.127 & 134.490 & 127.791 \\
\hline
\end{tabular}

Nota: en los años 1904, 1913 y 1935 se han incluido, en caso de existir datos, la matrícula de Santa María de Oza, ayuntamiento que se anexionó al municipio coruñés en 1912.

*En 1935, "Transportes” sólo recoge garajes y alquiler velocípedos.

Fuentes: BOPC $\mathrm{n}^{\circ} 76,5$ abril 1904; $\mathrm{n}^{\circ} 77,6$ abril 1904; $\mathrm{n}^{\circ} 78,7$ abril de 1904; $\mathrm{n}^{\circ} 79,8$ abril 1904; $\mathrm{n}^{\circ} 80,9$ de abril 1904;n81, 11 de abril 1904; nº82, 12 abril 1904; nº8, 13 abril 1904; nº 8414 abril 1904; n 171, 30 julio 1904 (OZA); nº 1013 mayo 1913; n 106, 9 de mayo de 1913; nº109 13 de mayo de 1913; n 113,17 de mayo de 1913; n 11723 de mayo de 1913; n 131, 9 de junio 1913; AMC. Caja 5121. Años 1920-21. Matrícula de la Contribución Industrial; COCINC. Matrícula de Industrial. Capital 1927 a 1932. Cámara de Comercio; Censo de Oza. 1934-1945. Cámara de Comercio; Censos de la capital. 1935 al 40. Cámara de Comercio.

Respecto a la ubicación de la oferta hotelera en sentido amplio, la mayoría se localizaba en el conocido como barrio de la Pescadería; es decir, en la zona más céntrica de la ciudad que rodea a la ciudad vieja y más histórica. Se trataba de calles situadas en el brazo más estrecho de la península herculina, donde se habían construido edificios de mayor altura, cercanos al puerto -centro de la vida mercantil y financiera de la ciudad- y a las paradas de coches y autobuses. Los hoteles más grandes y lujosos se emplazaban en un reducido sector cercano a los Cantones y la calle Real. Pese a la creciente popularidad de la playa de Riazor, esta zona todavía resultaba marginal para el negocio hotelero. En este sentido, A Coruña reaccionó con un cierto retraso respecto a otras ciudades turísticas del norte ${ }^{46}$. En conjunto, 63 establecimientos y 1655 plazas ofrecía la ciudad en 1930 (Cuadro 5).

46 Por ejemplo, el caso de San Sebastián en Larrinaga y Pastoriza (2009). 


\section{Cuadro 5 \\ TIPO DE ALOJAMIENTO EN A CORUÑA A PRINCIPIOS DEL AÑO 1930}

\begin{tabular}{|l|r|r|r|}
\hline Tipo & Número & Habitaciones & Plazas \\
\hline Fondas & 12 & 143 & 193 \\
\hline Hospedajes & 11 & 82 & 121 \\
\hline Hoteles & 40 & 926 & 1.341 \\
\hline Total establecimientos & 63 & 1.151 & 1.655 \\
\hline
\end{tabular}

Fuente: PNT (1929) y Anuario Regional del Norte de España (1932).

En A Coruña, los seis hoteles con mayor capacidad de hospedaje (más de 50 habitaciones) eran: Palace (78) Continental (70), Ferrocarrilana (60), Roma (60) ${ }^{47}$, Francia (60) y Atlantic (70). Salvo el Palace y el Atlantic, todos habían sido fundados antes de la Primera Guerra Mundial ${ }^{48}$. El hotel Palace, inaugurado en 1916 por José María Rodríguez Pardo, se convirtió en un hotel de referencia en la ciudad. Situado en un edificio señorial que presidía los Cantones y con fachada hacia la calle Real disponía de 50 habitaciones con cuarto de baño, distribuidas en tres plantas. Durante la década de 1920 los descendientes de José María Rodríguez ampliaron el establecimiento y lo convirtieron en el hotel más grande de la ciudad ${ }^{49}$. Esta compañía regía también el Café Oriental, en la planta baja del Hotel Palace, el Restaurante Ideal, en el entresuelo del mismo hotel, y un kiosco de refrescos instalado en el Parque de la Sociedad Sporting Club formando uno de los principales grupos empresariales hosteleros en la ciudad ${ }^{50}$. El emporio hostelero de la familia Rodríguez entró en dificultades a principios de los años treinta, cuando los beneficios se redujeron y el activo empresarial se contrajo ${ }^{51}$. Entre otros factores, la inestabilidad política de estos años y las consecuencias derivadas de la Gran Depresión (que afectó al movimiento de emigrantes por el puerto herculino) pudieron influir en las cuentas de la sociedad. Hay que tener en cuenta que la entrada y salida de emigrantes por el puerto de A Coruña pasó de más de 50.000 en 1920 a poco más de la décima parte en $1934^{52}$. Sin embargo, este hecho impactó de manera muy limitada en los hoteles de mayor lujo, inasequibles para la gran mayoría de emigrantes.

Con un capital muy superior, 254 mil pesetas, se constituyó la compañía La Parisiana, S.A. en 1920 con el fin de explotar el hotel Atlantic. El nuevo establecimiento constituía el fruto de la reforma de los pabellones del Cinema Salón Coruña, que ocupaba tres de los kioscos concedidos por el municipio en los jardines del Paseo Méndez Núñez y era propiedad de José Casal Juncosa, uno de los socios de la compañía. Su primer consejo de administración estaba formado por socios fundadores vinculados al republicanismo

47 AMC. C-8798. Licencias de apertura de establecimientos, año 1910.

48 Lindoso (2006: 331-346) y RMC, Libro 20 de Sociedades, Hoja n ${ }^{\circ} 541$, Inscripción $1^{\mathrm{a}}$ y $2^{\mathrm{a}}$, ff. 10-12.

49 El hotel se alojaría en el edificio conocido como "Casa Caruncho", construida en 1872. El Hotel sufrió un incendio en el año 1917 pero fue restaurado, véanse Hemeroteca EIG, "El Hotel que dominaba los Cantones", 19 de abril 2015 y Hemeroteca LVG, "Del Oriental al Palace Hotel”, 14 de febrero 2016.

50 RMC, Libro 24, fol. 174.177, $\mathrm{n}^{\circ} 710$.

51 ARG. Fondos Hacienda. Contribución de Utilidades. Balances de Hijos de José María Rodríguez (Hotel Palace), 1932-1935.

52 Vázquez (2000). 
gallego: Julio Wonemburger Canosa (empresario y concejal republicano del ayuntamiento de A Coruña), presidente; Santiago Casares Quiroga (abogado, político republicano y diputado en Cortes por A Coruña en 1931, 1933 y 1936), vocal; Eugenio Salgado Caamaño, secretario $^{53}$. En principio, se pretendía destinar el nuevo edificio a servicios de café, restauración, peluquería y galería fotográfica. Pero, en 1922, Casares Quiroga comunica al ayuntamiento que desean destinar la construcción a establecer un hotel dado que "A Coruña está falta de hoteles adecuados, carente de hospedajes cómodos y sumida en su propia indolencia" ${ }^{4}$. El hotel fue inaugurado en 1923 con 70 habitaciones muy confortables y 35 baños a su disposición. El edificio sin su mobiliario estaba valorado en más de 1,1 millones de pesetas según el balance del año 1931. El establecimiento contaba con su propio ómnibus. El patrón temporal ya apuntado se repite de nuevo en este establecimiento: los resultados económicos empeoraron en los años treinta ${ }^{55}$.

A principios del siglo XX, otro de los hoteles más selectos -y longevos- era el Hotel de Francia, fundado por Julián Mogín González, militar de carrera y propietario del establecimiento hasta $1911^{56}$. Contaba con 60 habitaciones y un restaurante donde acudía un público acomodado y de elevado poder adquisitivo para la época. Los hoteles de la competencia, por aquel entonces Ferrocarrilana, Europa, Suizo o Cuatro Naciones, apenas le hacían sombra. Asociado con José Piñeiro Vázquez fundó una sociedad para explotar el hotel con un capital inicial de 20.000 pesetas en 190957. Apenas dos años más tarde, la sociedad vendió el hotel a los hermanos Schucani de origen suizo y se desplazaron a Vigo. Allí habían adquirido del conservero José Ramón Curbera el Hotel Continental de Vigo, otro de los grandes palacios de la hostelería gallega, que regentaría en unión de su hermano Francisco ${ }^{58}$. Respecto al Hotel Continental coruñés, su historia se remonta al año 1885 cuando el comerciante Antonio Iglesias Pita y el fondista Manuel Losada Prado arrendaron la casa del empresario herculino Francisco Ortega y Soler, situada en la calle Olmos esquina Rúa Nueva, por tres años y 430 pesetas mensuales para establecer el citado establecimiento $^{59}$. Esta asociación resultó temporal e Iglesias se retiró al año siguiente cediéndole a Losada el mobiliario, la ropa y los efectos del hotel por ocho mil pesetas ${ }^{60}$. Losada, partícipe a su vez en el Gran Café Moderno coruñés, continuó en solitario explotando el negocio hostelero hasta que en 1909 se asoció con su hijo Vicente Manuel Losada García y fundaron la sociedad Gran Hotel Continental con un capital de seis mil pesetas. La empresa familiar cambiaría de nuevo su nombre por el original Hotel Continental en

53 RMC, Libro 23, fol. 125, nº 672

54 Hemeroteca EIG, "El desaparecido Atlántic Hotel y el nuevo hotel Atlántico", 1 de febrero 2015.

55 ARG. Fondos Hacienda. Contribución de Utilidades. Balances del Hotel La Parisiana S.A., 1931-1935. A finales de los años sesenta fue derruido y se construyó un nuevo hotel, el actual Hotel Atlántico, véase Hemeroteca EIG, "El desaparecido Atlántic Hotel y el nuevo hotel Atlántico", 1 de febrero 2015.

56 Tras la Guerra civil, cambió su nombre por Hotel España; en 1968 se trasladó a otro edificio de la misma calle. Funcionó hasta el año 2007. Demolido y rehabilitado, hoy en día se conoce como Blue Coruña, véase Hemeroteca LVG, "Del Hotel de Francia al Blue Coruña", 5 de enero 2014.

57 Esta compañía se denominó Mogín y Piñeiro, véanse RMC, año 1904, Hoja 312, Libro 12, f. 150 y ss y Libro 16 , fol. $185, \mathrm{n}^{\circ} 425$.

58 Hemeroteca LVG, "El Hotel Continental (II)", 26 de abril 2015.

59 Hemeroteca LVG, "El Hotel Continental (II)", 26 de abril 2015.

60 AHPC, José Asensio Centeno, leg. 10063 (1886). En el año 1930, el Gran Hotel Continental pertenecía a José F. Silva que databa la apertura del hotel en el año 1874, AMC. C-8479. Licencias de apertura. 
1914, duplicando su capital ${ }^{61}$. Entre los hoteles con más tradición de la población, nos encontramos con el Hotel Ferrocarrilana, objeto recurrente de muchas postales coruñesas de la época. Todavía en 1930, el periódico ABC recomendaba a sus lectores el Hotel Ferrocarrilana y el Atlantic Hotel para veranear en el norte de España; junto con otros de gran prestigio como el Gran Hotel de Santander y el Hotel Covadonga en Oviedo ${ }^{62}$. El germen del citado hotel coruñés estuvo constituido por la fonda del mismo nombre establecida por Blas Sainz en una céntrica casa de la calle Real ${ }^{63}$.

En vísperas de la Guerra civil, estos establecimientos se mantenían en activo aunque algunos habían cambiado de propietarios ${ }^{64}$. Junto a estas empresas hoteleras funcionaban en la ciudad una pléyade de pequeños hotelitos, fondas y pensiones. Es en este epígrafe donde la oferta se revela más dinámica, mientras que a la altura de 1923 la oferta de grandes hoteles ya se había consolidado. Hasta la I Guerra mundial predominaron los pequeños negocios familiares en la oferta hostelera y lúdica coruñesa, como revelan los datos de la Contribución Industrial y del Registro Mercantil. De hecho, entre 1820 y 1919, sólo se registraron seis sociedades dedicadas al hospedaje y quince que se dedicaban al negocio de la restauración y algún divertimento público (cafés, restaurantes, billares, una casa de baños). Entre los últimos, nos encontramos con históricos cafés como el Gran Café Méndez Núñez (1917) y La Terraza (1919) que adoptaron la forma de una sociedad anónima ${ }^{65}$. En conjunto, el crecimiento urbano y la pujanza de múltiples actividades terciarias habían impulsado la oferta de alojamiento, restauración y ocio en la ciudad de A Coruña en el periodo objeto de estudio.

\section{TURISMO URBANO Y PLANIFICACIÓN TERRITORIAL: LA CONSTRUC- CIÓN DE UNA CIUDAD JARDÍN}

En la España del primer tercio del siglo XX, pese a la mayor preocupación institucional por la actividad turística y con la salvedad de la isla de Mallorca y Cataluña, el movimiento turístico todavía no influía de manera considerable en la ordenación territorial ${ }^{66}$. Esto no implicaba un impacto nulo sobre la planificación urbana. Precisamente, en San Sebastián y Santander, la visita Real y el movimiento turístico que generó propiciaron la creación de áreas residenciales como las de La Concha-Ondarreta-Igueldo y la de El Sardinero-La Magdalena respectivamente. Aunque su notoriedad distaba de la que alcanzaban estas ciudades del Norte, A Coruña comenzaba a gozar de cierta fama en los circuitos turísticos. Tal y como hemos mencionado anteriormente, sus baños de ola y sus fiestas de María Pita atraían a una cohorte de fieles veraneantes durante la temporada estival. Los documentos

61 Lindoso (2006: 331-346) y RMC, Libro 20 de Sociedades, Hoja n ${ }^{\circ} 541$, Inscripción 1ª y 2a , ff. 10-12.

62 Hemeroteca ABC, "Veraneo en el norte de España", 5 de agosto 1930, p. 44.

63 AHPC, Francisco Ramos Vázquez, leg. 9873 (1883), n 252, f. 1609 y ss. véase AHPC, Manuel Devesa y Gago, año 1884, f. 3773 y ss.; RMC, año 1910, Hoja 453 libro 17 f. 149 y ss.; año 1909 Hoja 436 Libro 16 f. 313 y ss.; año 1900 Hoja 243 Libro 12, f. 165 y ss.

64 En la postguerra, se construyó el Hotel Finisterre (1941) sobre el solar de la antigua cárcel y a partir de la década de 1960, se derribaron el Hotel Palace, el antiguo Atlántico y desapareció el Hotel Embajador. Véase https://hotelportocobo.wordpress.com/2013/08/22/mirada-nostalgica-viejos-hoteles-de-a-coruna/

65 RMC, Libro 21 de Sociedades, Hoja $n^{\mathrm{o}} 573$, Inscripción $1^{\mathrm{a}}$ y $2^{\mathrm{a}}$, ff. 4-8.

66 Costa y Jiménez (2005). 
gráficos de la época nos muestran el arenal de Riazor plagado de bañistas y casetas de baños, mientras una muchedumbre circulaba por sus andenes. ¿En qué medida este turismo litoral influyó sobre el planteamiento urbano coruñés?

Recordemos que desde finales del siglo XIX, el crecimiento demográfico empezaba a rebasar los confines de la pequeña península que conformaba el núcleo originario de la población. La respuesta consistió en el crecimiento hacia las afueras de la ciudad. De este modo, se aprobaron los planes de urbanización de los dos ensanches en 1885 y 1910 que dibujaron los rasgos básicos del crecimiento urbano ${ }^{67}$. Durante las primeras décadas del siglo XX, la ciudad creció de manera espectacular en altura y superficie. En vísperas de la Guerra civil, A Coruña constituía la provincia gallega con mayor parque de viviendas en los núcleos urbanos, en torno a 84 mil viviendas en sus núcleos urbanos frente a los 77 mil de Pontevedra, su principal seguidora ${ }^{68}$.

Asimismo, la expansión urbana se prolongó hacia los municipios limítrofes, donde se mantenía la naturaleza rural y marítima de la población salpicando el paisaje de pequeños ranchos de pescadores rodeados de huertas. Durante el primer tercio del Novecientos, el trazado de la zona de Riazor se alteró radicalmente. El espacio que conformaban las casas de baños privadas y municipal se dotó de una serie de servicios e infraestructuras que lo integraron en la red urbana: alcantarillado, alumbrado, agua corriente, demolición de viejas construcciones para ampliar el andén de Riazor - precedente del actual paseo marítimo- y la instalación de jardines que estaban cambiando la faz del litoral noroeste. El próximo paso consistía en crear un parque público según el proyecto de reforma y ampliación del Ensanche, aprobado por Real Decreto de 24 de mayo de $1910^{69}$.

Sin embargo, a principios de la década de 1920 triunfaron otro tipo de planteamientos: aquellos que empezaban a considerar este entorno costero como área de expansión residencial y explotación turística. Ejemplo de este giro estratégico fue el proyecto de la ciudad jardín, a medio camino entre lo que vulgarmente se conoce como un "pelotazo" urbanístico y un bucólico plan que perseguía el disfrute de la naturaleza y las bondades del mar y la playa en las proximidades del centro de la ciudad.

El concepto de ciudad jardín tiene su origen en el reformador social Ebenezer Howard. Este británico expuso su modelo urbano en 1898 con la publicación de «Tomorrow a Paceful Path to Real Reform», obra que sería reeditada en 1902 con el título de Garden Cities of Tomorrow ${ }^{70}$. Howard propuso la construcción de un nuevo modelo de ciudad, capaz de cubrir las necesidades económicas modernas pero sin romper la relación con la naturaleza. En efecto, la ciudad jardín se planteaba una nueva concepción de construir y planificar ciudades a través de viviendas unifamiliares o cottages, que eran consideradas como el alojamiento ideal para todas las clases sociales ${ }^{71}$. La ciudad jardín debía de completarse con un conjunto de curvas elegantes y de armoniosas calles plantadas de árboles y bordeados de césped. Entre finales del siglo XIX y principios del siglo XX, este concepto

67 Gallego y González (1975).

68 Tafunell (2005).

69 AMC, Ordenanzas para las construcciones en la zona del Ensanche de La Coruña, La Coruña, Imprenta de Tierra Gallega, San Andrés, 153, Año 1910.

70 Siguiendo la tesis de Arriola (1984).

71 Barreiro (1991: 59). 
se difundió por el continente europeo, aunque cada país lo adaptó a su propia estructura urbana. La introducción de este modelo constructivo en España siguió sus propias pautas, algo diferentes al modelo general europeo: estuvo siempre ligado a las clases acomodadas y solía estar ubicado en las afueras de las ciudades -en los llamados parques urbanizados-. Por tanto, la mayoría de proyectos de construcción de ciudades jardín en España dieron lugar a la creación de grupos de viviendas que acabaron siendo destinadas a familias de la clase media-alta profesional. Incluso en algunos casos, donde se había planificado la construcción de casas obreras se terminaron construyendo urbanizaciones caras y asequibles solo a las capas más altas de la población, caso de las colonias del Retiro (1920) o de Chamartín (1928) en Madrid.

Imitando las tendencias europeas, se empezaron a aplicar en A Coruña modelos urbanísticos derivados de la ciudad jardín inglesa que "buscaba descentralizar el crecimiento de las grandes ciudades y promover una oferta de viviendas sociales para los obreros"72. Pero, al igual que ocurría en otras ciudades españolas, el modelo europeo se aplicó en una doble vertiente. De un lado, se construyeron nuevas barriadas de casas baratas unifamiliares, como por ejemplo las del Campo de Marte. De otro lado, se promocionaron nuevos barrios residenciales destinados a familias de clase media-alta como era el caso de Ciudad Jardín en el entorno de Riazor. Este proyecto, que proponía la construcción de 76 chalets con cuatro diseños diferentes en parcelas de $500 \mathrm{~m}^{2}$, fue impulsado por un grupo de vecinos coruñeses en el Círculo de Artesanos en noviembre de 1921 con una representación del Ayuntamiento de la ciudad, de la prensa y de otras fuerzas vivas. El grupo promotor estaba compuesto por hombres de gran prestigio social y empresarial y, en algunos casos, herederos de sagas familiares que habían contribuido al desarrollo económico de la ciudad herculina desde tiempo atrás. Se trataba de Luis Cornide Quiroga, Canuto Berea Rodrigo, José Agudín Aspe, Francisco Vázquez Lens, José Piñeiro Vázquez, Gabriel López Companioni, Eduardo Rodríguez Losada, Jacobo Correa Oliver, Ricardo Pernas Varela y Manuel Fernández Morales. La presentación social del proyecto urbanístico fue acogida con gran entusiasmo por las fuerza vivas de la ciudad, ya que "reconciliaba el pueblo con el mar y fundaba su principal encanto en ofrecer como horizonte, desde todos los chalets, el insuperable espectáculo de la entrada de La Coruña, la Torre de Hércules, las playas y las lejanías del puerto con los alegres pueblecillos de que están sembradas las vecinas montañas"73.

Estos emprendedores presionaron al ayuntamiento a través de la prensa local y de diferentes círculos y asociaciones de la ciudad con el fin de que se recalificasen los terrenos y se permitiese la construcción de viviendas. En su mayoría, los componentes del grupo estaban bien conectados con las elites empresariales de la ciudad y con la corporación municipal que tenía que aprobar las licencias de obras y financiar las infraestructuras básicas del nuevo ensanche. El abogado Luis Cornide Quiroga fue uno de los miembros más activos. Fue secretario de la Sala de la Audiencia Territorial y, posteriormente, Secretario de Gobierno del Tribunal Supremo. Este diputado republicano formó parte en el terreno profesional de los consejos de administración de importantes empresas del tejido industrial gallego (Fábricas Coruñesas de Gas y Electricidad, Sociedad General Gallega

72 Precedo (1990: 269).

73 Estatutos de la Sociedad Coruñesa de Urbanización, p. 2. 
de Electricidad, Compañía de Tranvías de La Coruña). También formaba parte del grupo promotor Canuto Berea, nieto de empresarios y emprendedor a su vez en la compañía familiar de instrumentos musicales y otras iniciativas en la ciudad ${ }^{74}$. Otro de los impulsores del proyecto de Ciudad Jardín fue José Agudín Aspe, cuya actividad empresarial aparece vinculada a la de varias firmas industriales y de servicios urbanos ${ }^{75}$. Por su parte, Francisco Vázquez Lens ejercía de armador de pesca y comerciante mientras participaba en varias sociedades como la Compañía de Tranvías de La Coruña ${ }^{76}$. Entre los empresarios más relacionados con la hostelería, debemos mencionar a José Piñeiro Vázquez, socio de Julián Mogín en el primer Hotel de Francia. Por su parte, el puesto de concejal del comerciante Manuel Fernández Morales, vinculado a la emblemática Torres y Saez de A Coruña, permitía a la sociedad promotora, Coruñesa de Urbanización ${ }^{77}$, contar con información de primera mano sobre el avance de las obras de urbanización de Ciudad Jardín y la gestión de las licencias municipales ${ }^{78}$. Por último, entre los artífices del proyecto, encontramos el polifacético proyectista de Ciudad Jardín, Eduardo Rodríguez-Losada Rebellón, arquitecto y compositor coruñés, y a los hermanos Gabriel y Manuel López Companioni. El último ocupó el cargo de concejal en varias ocasiones ${ }^{79}$.

En noviembre de 1921, el arquitecto municipal y la comisión del Ensanche emitieron sendos informes favorables, señalando que si se modificaba el trazado original del parque podría ser compatible con la promoción de la urbanización. Con un capital de un millón de pesetas, se iniciaron las grandes obras de apertura de avenidas y la construcción de los primeros chalets en marzo de $1922^{80}$. A finales de la década, Ciudad Jardín estaba ya formada por "más de 40 chalets, dos grandes edificios destinados a la enseñanza y educación moral, y el Observatorio Meteorológico" 81 . El rápido acondicionamiento del entorno físico y la instalación de los servicios de agua y luz por parte de la Compañía de Aguas y las Fabricas Coruñesas de Gas y Electricidad convirtieron en poco tiempo los montes y las huertas en una zona urbanizada. A finales de 1923 ya estaba completamente terminado el tendido de la vía del tranvía ${ }^{82}$, de modo que su llegada se usó como reclamo publicitario para promocionar el nuevo barrio residencial.

En un primer momento, los impulsores de la urbanización expusieron abiertamente que Ciudad Jardín no pretendía ser un barrio residencial para las elites de la ciudad sino que el objetivo era que cualquier trabajador con ahorro y tesón pudiera acceder a una vivienda en

74 RMC, libro 5, hoja 70, inscripción 1ª, fol. 35; Meijide Pardo (1997: 311-322); Giadás Álvarez (1997: 207) y Martínez (dir.) (2006: 364); Facal (1986: 53).

75 RMC, libro 11, hoja 227, inscripción $1^{\text {a }}$, fol. 331, libro 13, hoja 284, inscripción $1^{\text {a }}$, fol. 72 , libro 13 , hoja 307 , inscripción $1^{\mathrm{a}}$, fol. 138; libro 15 , hoja 403 , inscripción $1^{\mathrm{a}}$, fol. 315 .

76 RMC, libro 14, hoja 366, inscripción $1^{\text {a }}$, fol. 176, y RMC, libro 14, hoja 405, inscripción $1^{\text {a }}$, fol. 337.

77 En 1923 se constituyó la Sociedad Coruñesa de Urbanización SA. RMC, libro 26, hoja 731, inscripción $1^{\mathrm{a}}$, fol. 11 .

78 Giadás (1997: 381 y 389).

79 Fernández González (2005: 23), Lindoso (2005: 423-424) y Arroyo (2001: 17).

80 González Catoyra (1994: 179).

81 AMC, Obras públicas y expropiaciones. Expediente de Obras sobre la construcción de una Ciudad Jardín con terrenos del antiguo lugar del Peruleiro, Instancia al Ayuntamiento de La Coruña de Luis Cornide Quiroga, 18 de junio de 1929, c. 463.

82 González Catoyra (1994: 179). 
la zona ${ }^{83}$. Obviamente, resulta difícil creer que un asalariado medio que cobraba alrededor de 5 pesetas al día y tenía que hacer frente a graves problemas de subsistencia, pudiera plantearse la compra de una vivienda cuyo coste alcanzaba por término medio las 40 mil pesetas $^{84}$. Por tanto, buena parte de sus compradores pertenecieron a la sociedad coruñesa pudiente del momento, entre ellos algunos de sus inspiradores ${ }^{85}$. Sin embargo, realizada ya la primera fase y construidos los primeros chalets a ambos lados de las avenidas recién abiertas, el ritmo de las obras se ralentizó debido a la situación económica ${ }^{86}$.

La regresión de la economía española en los años treinta afectó de lleno al sector de la construcción, dando lugar a la paralización de muchas obras y el consiguiente aumento del paro. Asimismo, ello repercutió negativamente en las ventas de chalets. A las dificultades existentes se unió la huelga del ramo de la construcción que paralizó las obras durante meses. A principios de la década de 1930, como en otros puntos de España, tuvieron lugar en A Coruña movimientos huelguísticos de gran relevancia y graves consecuencias económicas ${ }^{87}$. La crisis había provocado un desvío de las inversiones inmobiliarias hacia otros activos de mayores rendimientos. Con esta coyuntura la sociedad urbanizadora se vio obligada a restringir gastos y limitar su actividad a la mera conservación de las obras existentes. En paralelo, la empresa mantuvo un pulso con el ayuntamiento durante estos años, reclamando una mayor atención en cuanto al cumplimiento de los servicios y obligaciones municipales en esta nueva barriada y los pagos que la corporación le adeudaba por obras realizadas ${ }^{88}$. Tras la Guerra civil, la situación de la sociedad mejoró notablemente con la reactivación del sector de la construcción y el mercado inmobiliario ${ }^{89}$. Pero, lejos de sus aspiraciones iniciales, la Ciudad Jardín se había transformado en uno de los barrios residenciales más elitistas de la ciudad en el marco incomparable del entorno marítimo de Riazor y, con el tiempo, adquirió una posición céntrica en la ciudad mientras los barrios obreros tendían a confinarse en las afueras. Un comportamiento similar podemos observarlo en San Sebastián donde la planificación urbana tendió a reservar la costa para residencia de las élites locales e, incluso, los turistas ${ }^{90}$.

\section{CONCLUSIONES}

Durante el primer tercio del siglo XX, el turismo conforma una actividad social incipiente en España cuyo potencial económico tardó en ser reconocido oficialmente y en ser objeto de atención política. Dentro de este contexto, A Coruña se colocó en el naciente mapa turístico nacional en torno a dos grandes activos, explotados ya desde décadas atrás: sus playas urbanas y las actividades lúdico-recreativas vinculadas al verano coruñés. La

83 Cao (1930).

84 Barreiro (1991: 175).

85 AMC, Padrón 1940, sig. 1478, Distrito 6, secc. 53-58.

86 RMC, libro 28 , hoja 731 , inscripción $2^{\mathrm{a}}$, fol. 59.

87 ARG, Hacienda, Contribución de Utilidades, leg. 781; Memorias de la Sucursal de A Coruña del Banco de Bilbao, 1931-1933; Memoria de la Sociedad Coruñesa de Urbanización, 1932; González Catoyra (1994: 242).

88 AMC, Obras Públicas y Expropiaciones. Expediente de Obras sobre la construcción de una ciudad jardín con terrenos del antiguo lugar del Peruleiro, 18 de junio de 1929, c. 463.

89 ARG, Hacienda, Contribución de Utilidades, leg. 775. Memoria de la sociedad, 1940.

90 Cirer (2014). 
temporada estival y todo lo que la rodeaba -casas de baños, fiestas de verano, espectáculos y toros- se convirtieron en objeto de campañas públicas de promoción del turismo urbano herculino con el fin de atraer tanto al turista nacional como al extranjero y desarrollar actividades empresariales y urbanísticas relacionadas. La casi orfandad estadística sobre estas cuestiones no nos permite cuantificar el número de visitantes que recibió la ciudad durante el periodo objeto de estudio. Pero todo apunta a que al menos hasta la década de los treinta, las autoridades municipales consiguieron exitosos resultados -aunque no tan satisfactorios como en otras capitales del Norte que disfrutaban de una clientela selecta y cuantiosa-. A la sombra del turismo y el ocio, la ciudad se transformó y se creó actividad económica y empresarial. En conjunto, el stock turístico coruñés se incrementó tanto desde el punto de vista público como privado. Si bien el número de casas de baños apenas creció, sí mejoraron sus instalaciones y su oferta lúdica. Con respecto a la hostelería, experimentó su mayor crecimiento hasta el citado decenio de 1930. La oferta hotelera de mayor entidad y categoría se consolidó a comienzos de la década de 1920. No obstante, hasta los años treinta, el crecimiento hotelero estuvo protagonizado por fondas, casas de huéspedes, pensiones y pequeños hoteles que incrementaron su participación en el patrimonio urbano. Muchas de ellas estuvieron al servicio del tráfico migratorio gallego hacia las Américas. Esta dependencia condicionaría el futuro del hospedaje de categoría inferior cuando la Gran Depresión frenó esta corriente. Por último, desde el punto de vista de la planificación territorial, el impacto turístico se dejó sentir en las zonas con mayor potencial como la playa de Riazor, donde se situó la elitista Ciudad Jardín. En este sentido, imitaron a pequeña escala lo acontecido en ciudades como San Sebastián y Santander donde el ordenamiento urbano se vio claramente afectado por su desarrollo turístico.

En conjunto, este estudio pone en evidencia que en zonas a priori menos turísticas de España se configuraron también las bases de un turismo moderno a principios del siglo $\mathrm{XX}$. En este proceso tanto agentes privados como públicos trataron de poner en valor las ventajas competitivas de cada territorio. Este desarrollo fue anclado al crecimiento urbano, la mejora en las condiciones de vida y el desarrollo de la cultura del ocio. El caso coruñés se revela como un ejemplo (al margen de los tradicionales lugares de veraneo como San Sebastián, Santander o Baleares) de que el turismo en la España del periodo era una industria no solo con potencial, sino con repercusión efectiva en los resultados económicos regionales y locales.

\section{FUENTES Y BIBLIOGRAFÍA}

\subsection{Fuentes}

AHPC: Archivo Histórico de Protocolos de A Coruña

AMC: Archivo Municipal de A Coruña

ARG: Archivo del Reino de Galicia

BOPC: Boletín Oficial de la Provincia de A Coruña

COCINC: Cámara de Comercio, Industria y Navegación de A Coruña

Hemeroteca ABC

Hemeroteca EIG (El Ideal Gallego) 
Hemeroteca LOC (La Opinión de A Coruña)

Hemeroteca LVG (La Voz de Galicia)

Memorias de la Sucursal de A Coruña del Banco de Bilbao

RMC: Registro Mercantil de A Coruña

\subsection{Bibliografía}

ALONSO ÁLVAREZ, L., LINDOSO TATO, E. y M. VILAR RODRÍGUEZ (2008): Construyendo empresas. La trayectoria de los emprendedores coruñeses en perspectiva histórica, 1717-2006. A Coruña, CEC, 2 vols.

ALONSO ÁlVAREZ, L., LINDOSO TATO, E. y M. VILAR RODRÍGUEZ (2011): $O$ lecer das augas. Unha historia dos balnearios de Galicia, 1700-1936. Vigo, Galaxia.

Anuarios Regionales de España (1932): Anuario regional descriptivo, informativo y seleccionado de la industria, comercio, agricultura, profesiones, arte y turismo del Norte de España: comprende las provincias de Galicia, Asturias, Santander y Vascongadas.

ARRIOLA AGUIRRE, M. P. (1984): «La Ciudad Jardín de Vitoria-Gasteiz», Lurralde, $\mathrm{n}^{\mathrm{o}}$ 7, pp. 287-296.

ARROYO MARTÍN, J.V. (2001): Estudios bancarios: El Banco de La Coruña entre 1918 y 1970. Bilbao, Archivo Histórico del BBVA.

BARREIRO PEREIRA, P. (1991): Casas Baratas. La vivienda social en Madrid 19001939. Servicio de Publicaciones del Colegio Oficial de Arquitectos de Madrid.

CAO MOURE, J. (Eds.) (1930): Libro de oro de la provincia de La Coruña. Vigo, Editorial PPKO.

CASES MÉNDEZ, J. I. y MARCHENA GÓMEZ, M. (2005): «Turismo urbano», en Bayón, F. (Dir.). 50 años de turismo español. Un análisis histórico y estructural. Madrid, Centro de Estudios Ramón Areces, pp. 653-672.

CASTILlO, Á. DEL (1933): «Galicia: La Coruña. Su riqueza monumental», Revista Española de Turismo, Año 2, no 4-5, pp. 17-19.

CIRER, J.C. (2014): «Spain's new coastal destinations. 1883-1936: The mainstay of the development of tourism before The Second World War», Annals of Tourism Research, vol. 45, pp. 18-29.

COSTA PÉREZ, A. y JIMÉNEZ PAZ, J.L. (2005): «Turismo y urbanismo», en BAYÓN, F. (Dir.). 50 años de turismo español. Un análisis histórico y estructural. Madrid, Centro de Estudios Ramón Areces, pp. 465-502.

COUMES-GAY, A. (1877): Guía de La Coruña . A Coruña, Establecimiento Tipográfico de D. Domingo Puga.

Dirección General de Actividades y Empresas Turísticas (1972): Guía de Hoteles España 1973. Madrid.

Estatutos de la Sociedad Coruñesa de Urbanización. La Coruña, Imprenta Roel, 1923.

FACAL RODRIGUEZ, M.J. (1986): La banca en Galicia durante la época de la Restauración: el Crédito Gallego. Tesis licenciatura. Santiago de Compostela, Universidad de Santiago.

FAGINAS ARCUAZ, R. (1890): Guía-indicador de La Coruña y de Galicia para 1890-91 (año I). A Coruña, Vicente Abad. 
FERNÁNDEZ GONZÁLEZ, A. (2005): «De la roca a la cuerda. Orígenes y desarrollo de la industria mejillonera en Galicia (1946-2005)». Ponencia presentada a la sesión Instituciones y Empresas en las industrias marítimas (siglos XVI-XX), VIII Congreso de la Asociación Española de Historia Económica. Santiago de Compostela.

GALLEGO JARRETO, M. y GONZÁLEZ CEBRIÁN TELLO, J. (1975): «Análisis del desarrollo urbano de La Coruña», Ciudad y Territorio, no 1-2, pp. 67-93.

GARRIDO MORENO, A. (1998): El arquitecto Rafael González Villar. A Coruña, Diputación Provincial.

GIADÁS ALVAREZ, L. (1997): La vida política municipal en La Coruña entre 1900 y 1931. A Coruña, Edicios do Castro.

GIL DE ARRIBA, C. (1992): Casas para baños de ola y balnearios marítimos en el litoral montañés, 1868-1936. Santander, Universidad de Cantabria.

GIL DE ARRIBA, C. (2007): «Las playas y el fenómeno urbano: asimilación y uso histórico. De los baños de ola al ocio contemporáneo», en Estrada, J.L. et al. (Dir.). Playas urbanas. IV Curso Internacional Relaciones Puerto-Ciudad. Autoridad Portuaria de Santander, pp. 34-48.

GONZALEZ CATOYRA, A. (1994): Cronología coruñesa: 1901-1993: (de los tranvías con tracción de sangre a la Domus o Casa del Hombre). A Coruña.

Guía práctica para el viajero de la Sociedad de Hoteleros, Fondistas y similares legalmente constituida en La Coruña. A Coruña, Imprenta y Papelería de F. García Ybarra, 1911 .

https://hotelportocobo.wordpress.com/2013/08/22/mirada-nostalgica-viejos-hoteles-de-acoruna/

LARRINAGA, C. y PASTORIZA, E. (2009): «Dos balnearios atlánticos entre el fin de siglo y la crisis del treinta, San Sebastián y Mar del Plata. Un ejercicio comparativo». Cuadernos de Historia Contemporánea, nº 38, pp. 277-310.

LARRINAGA, C. (2009): «Baños de ola: una moda para privilegiados». La Aventura de la historia, $\mathrm{n}^{\circ} 129$, pp. 64-68.

LARRINAGA, C. (2015): «De las playas frías a las playas templadas: la popularización del turismo de ola en España en el siglo XX». Cuadernos de Historia Contemporánea, $\mathrm{n}^{\mathrm{o}} 37$, pp. 67-87.

LINDOSO TATO, E. (2005): El factor empresarial en la Galicia atlántica, 1820-1913. Tesis doctoral. A Coruña, Facultad de Ciencias Económicas y Empresariales de la Universidad de A Coruña.

LINDOSO TATO, E. (2006): Los pioneros gallegos. Bases del desarrollo empresarial 1820-1913. Madrid, Lid.

MARTÍNEZ LÓPEZ,A. (Dir.) (2006): Compañía de Tranvías de La Coruña (1876-2005). Redes de transporte local. Madrid, Lid.

MARTÍNEZ, A. y PIÑEIRO, C. (2001): «Empresas y servicios públicos: la creación de una infraestructura de transporte urbano, A Coruña 1876-1925». Revista Galega de Economía, vol. 10 (1), pp. 249-278.

MEIJIDE PARDO, A. (1997): «Casas de baños de mar en La Coruña del siglo XIX», en MEIJIDE PARDO, A. Temas y personajes de la historia coruñesa contemporánea. A Coruña, Diputación de A Coruña, pp. 311-322. 
MONTERROSO DEVESA-JUEGA, J.M. (1992): «Casas de baños de Riazor na Coruña de antano: La Primitiva». Anuario Brigantino, ${ }^{\circ}$ 15, pp. 141-148.

PALOU, S. (2017): «La primera experiencia de política turística autonómica en Cataluña», I Congreso de Historia del Turismo, Poio (Pontevedra), 6-9 de junio.

PATRONATO NACIONAL DE TURISMO (PNT) (1929): Guía Oficial de Hoteles, Pensiones, Casas de Viajeros, Restaurante, Bares y Garages (publicado en virtud de $R$. O. circular de la Presidencia del Consejo de Ministros). Madrid.

PELLEJERO MARTÍNEZ, C. (2016): «De incomparable Station d'Hiver a Costa del Sol: Málaga, 1875-1973». Revista de Historia de la Economía y de la Empresa, nº 10, pp. 253-283.

PRECEDO LEDO, A. (1990): La Coruña metrópoli regional. A Coruña, Fundación Caixa Galicia.

TAFUNELL, X. (2005): «Urbanización y vivienda», en CARRERAS, A. y X. TAFUNELL (Comp.) Estadísticas históricas de España, siglos XIX-XX. Bilbao, Fundación BBVA, vol. I, pp. 455-499.

TETTAMANCY, F. (1900 [1994]): Apuntes para la Historia Comercial de La Coruña. A Coruña, Ayuntamiento de A Coruña, Edición facsimilar.

VALLEJO, R., LINDOSO, E. y VILAR, M. (2016): «Los antecedentes del turismo de masas en España, 1900-1936». Revista de Historia de la Economía y de la Empresa, $\mathrm{n}^{\circ} 10$, pp. 137-190.

VALVERDE Y ÁLVAREZ, E. (1886): Plano y guía del viajero en Coruña, Betanzos y Ferrol. Madrid, Imp. de Fernando Cao y Domingo de Val.

VÁZQUEZ GONZÁLEZ, A. (2000): La emigración gallega a América, 1830-1930. Tesis doctoral. Santiago de Compostela, Universidad de Santiago de Compostela.

VÁZQUEZ GONZÁLEZ, A. y DE JUANA LÓPEZ, J. (2005): «Población y emigración en Galicia», en PRADA RODRÍGUEZ, J. y DE JUANA LÓPEZ, J. (Coord.), Historia contemporánea de Galicia. Barcelona, Ariel, pp. 393-440.

VIOLIER, Ph. y ZÁRATE, M.A. (2007): «Turismo urbano y políticas para su gestión en Francia y España», Estudios Geográficos, n 262, pp. 321-347.

WALTON, J. K. (1997): «The seaside resorts of Western Europe, 1750-1939», en FISHER, S. (Ed.) Recreation and the sea. Exeter, University of Exeter Press, pp. 36-56. 